\title{
In Silico Prediction of Isoliquiritigenin and Oxyresveratrol Compounds to BCL-2 dan VEGF-2 Receptors
}

\author{
Roihatul Mutiah*, Muhammad Fawwaz Hariz, Yen Yen Ari Indrawijaya, Burhan Ma'arif \\ Department of Pharmacy, Faculty of Medical and Health Sciences, Maulana Malik Ibrahim State Islamic University of \\ Malang, Indonesia
}

\begin{abstract}
Isoliquiritigenin and oxyresveratrol are compounds that have been reported to have anticancer activities. This study aimed to predict cytotoxic activity, toxicity and physicochemical properties of the compounds isoliquiritigenin and oxyresveratrol. Prediction of physicochemical properties referred to Lipinski rules of five using the pkCSM online tool. Prediction of compounds toxicity using Protox II online tool while ligand interaction with receptors using Molegro Virtual Docker (MVD). Vascular Endothelial Growth Factor Receptor-2 (VEGFR-2) (PDB: 2RL5) and B Cell Lymphoma BCL2 (PDB: 4AQ3) were used as target cancer receptor proteins. In silico predictive results showed that oxyresveratrol and isoliquiritigenin complied with Lipinski rules of five, predictive values of $\mathrm{LD}_{50}$ between $500-2000 \mathrm{mg} / \mathrm{kg}$ respectively $1560 \mathrm{mg} / \mathrm{kg}$ and 1048 $\mathrm{mg} / \mathrm{kg}$. The docking result was in the form of bound energy described by Rerank Score (RS). A compound having a small RS value was predicted to have greater activity. RS of oxyresveratrol on 2RL5: -73.0413 and 4AQ3: -87.9985, while isoliquiritigenin on 2RL5: -68.0282 and 4AQ3: -78.5041 . The cytotoxic activity of oxyresveratrol was also shown by hydrogen bonds in active amino acids (2RL5: Cys 919 in 4AQ3: Tyr 67). From docking results of both compounds, oxyreveratrol had greater activity than isoliquiritigenin to both target cancer receptor proteins and complied Lipinski rules of five and have a low toxicity.
\end{abstract}

Keywords : cytotoxicity, toxicity, isoliquiritigenin, oxyresveratrol, in silico

\section{INTRODUCTION}

Cases of cervical cancer in the world are estimated to have more than 570,000 with $83 \%$ caused by Human Papilloma Virus (HPV) and twothirds of these cases occur in developing countries (Martel, et al., 2017). Chemotherapy and radiotherapy are used as therapies for cervical cancer (Liu, 2018). The resistance of chemotherapy drugs including cisplatin has become an important problem in the treatment of cervical cancer (Wang, et al.,
2015). So that it can be found and developed anti-cancer drugs from natural ingredients (Kinghorn, 2008). Isoliquiritigenin and oxyresveratrol are compounds that have been isolated from Eleutherine palmifolia (L.) Merr, Glycyrrhiza uralensis,

Submitted: January 22, 2019

Revised: March 7, 2019

Accepted: March 11, 2019

*Corresponding author: roiha@farmasi.uin-malang.ac.id 
Sinofranchetia chinensis, Dalbergia odorifera and Glycine max (L.) Merr. Both of these compounds have been reported to have anticancer activities in vitro (Minggarwati, 2018, Ayeka, et al., 2016; Cao, et al., 2004; Pan, et al., 2000; Chan, et al., 1998; Kape, et al., 1992). The development of anticancer drugs that have specific molecular targets is one of the strategies to overcome cancer. The two main targets in this study are apoptosis induction cancer cell and antiangiogenic. Apoptosis is programmed cell death which plays an important role in maintaining the body's homeostasis. Failure of apoptosis is a major factor in cancer cell malignancy. The approach to treating cancer through the mechanism of apoptosis induction has been known to be able to prevent promotion, progression and re-emergence of cancer (Rastogi and Sinha, 2009). Implementation of apoptosis clinical activities produces the effects of chemotherapy and chemopreventive (Sun, et al., 2004). Apoptosis in the mitochondrial pathway has two pathways, the extrinsic pathway and intrinsic pathway. The extrinsic pathway involves Fas, while the intrinsic pathway involves cytochrome c (cyt-c) released from mitochondria $(\mathrm{Ku}-$ mar, 2005). The intrinsic pathway is mediated by the Bcl-2 family. This apoptotic regulation is carried out by antiapoptotic (Bcl-2 and Bcl-xl) and pro-apoptotic (Bax and Bak) proteins. These proteins play a role in the regulation of apoptosis through regulation of release cyt-c. The expression of Bcl-2 or Bcl-xl prevents the release of cyt-c from mitochondria. Direct addition of Bax to mitochondrial isolates can induce the release of cyt-c (Igney and Krammer, 2002). In the cytosol cyt-c will form a complex with apaf1 (Apoptotic Protease Factor-1), ATP and procaspase-9. This complex is called the apoptosome. Cancer growth is also often associated with expression of Vascular Endothelial Growth Factor Receptor-2 (VEGFR-2) as a proangiogenic pathway to increase the angiogenesis stage including vascular permeability, endothelial cell survival, proliferation, migration or invasion of surrounding tissues, and formation capillary blood vessels (Fer- rara, 2009). The pathway mechanism VEGFR-2 is blockade of activation of tyrosine kinase (Hoi, et al., 2014). Receptor tyrosine kinases can mediate Angiogenesis (Jeltsch, et al., 2013). In this study, we performed the prediction of cytotoxic activity, toxicity and physicochemical properties of the two compounds to VEGFR-2 and BCL-2 receptors.

\section{METHODS}

\section{Software}

Chem Bio Ultra 12.0, pkCSM on line tool, Protox II online tool, Molegro Virtual Docker 5.5, Molegro Data Modeller 3.0.

\section{Target and Template Selection}

PDB of BCL-2: 4AQ3 and VEGFR-2: 2RL5 taken from Protein Data Bank (https://www.rcsb. org). The SMILES code is taken from PubChem Compound (https://pubchem.ncbi.nlm.nih.gov/).

\section{Prediction of Physicochemical Properties and Toxicity}

Physicochemical properties and toxicity prediction used the SMILES format and pkCSM online tool (Pires, 2015), then categorized into Lipinski rules of five. Toxicity predictions used the Protox II Online tool anad categorized as toxicity classes (Drwal, 2014).

\section{Molecular Docking Study}

Docking is done using Molegro Virtual Docker software 5.5. Identification of ligand bonds is carried out by evaluating repeated identification and estimating bond energy with a macromolecule (CLCbio, 2013). Isoliquiritigenin and oxyresveratrol compounds drawn 2D first then transferred into a 3D shape using Ultra Chem 12.0. Validation of methods done by ligands already present in proteins VEGFR-2 (PDB: 2RL5) and BCL-2 (PDB: 4AQ3) and performed the docking process. Programs that can return poses below RMSD value less than $2 \AA$ is considered to have performed successfully (Hev- 
ener, et al., 2009). Furthermore, the existing ligand are replaced with isoliquiritigenin and oxyresveratrol by conducting alignment and docking simulations carried out for each of these compounds. Protein 2 RL5 has a chain protein and $4 \mathrm{AQ} 3$ has six chains and each of which is filled with ligand. The results obtained are the value of root mean square deviation (RMSD) and rerank score (RS), which is the bond energy required in the ligand-receptor interaction process (Siswandono, 2016). Bond energy indicated the amount of energy needed to form bonds between ligands and receptors. The lower the bond energy, the more stable the bond. The more stable the ligand bond with the receptor, the higher the activity (Hardjono, 2012).

\section{RESULTS}

\section{Prediction of Physicochemical Properties and Toxicity}

The results of absorption and permeability prediction to oxyresveratrol and isoliquiritigenin compounds using Lipinski rules of five showed that the four physicochemical properties were $\log p<5$, Molecular Weight $<500, \mathrm{H}$ bond donor $<5$ and $\mathrm{H}$ bond acceptor $<10$. Based on these results, two compound meet the Lipinski rules of five requirements so it can be predicted that the compounds will be easily absorbed and have high permeability (Lipinski, et al., 1997). Physicochemical Properties prediction is presented in Table 1.

Table 1. Prediction of physicochemical properties.

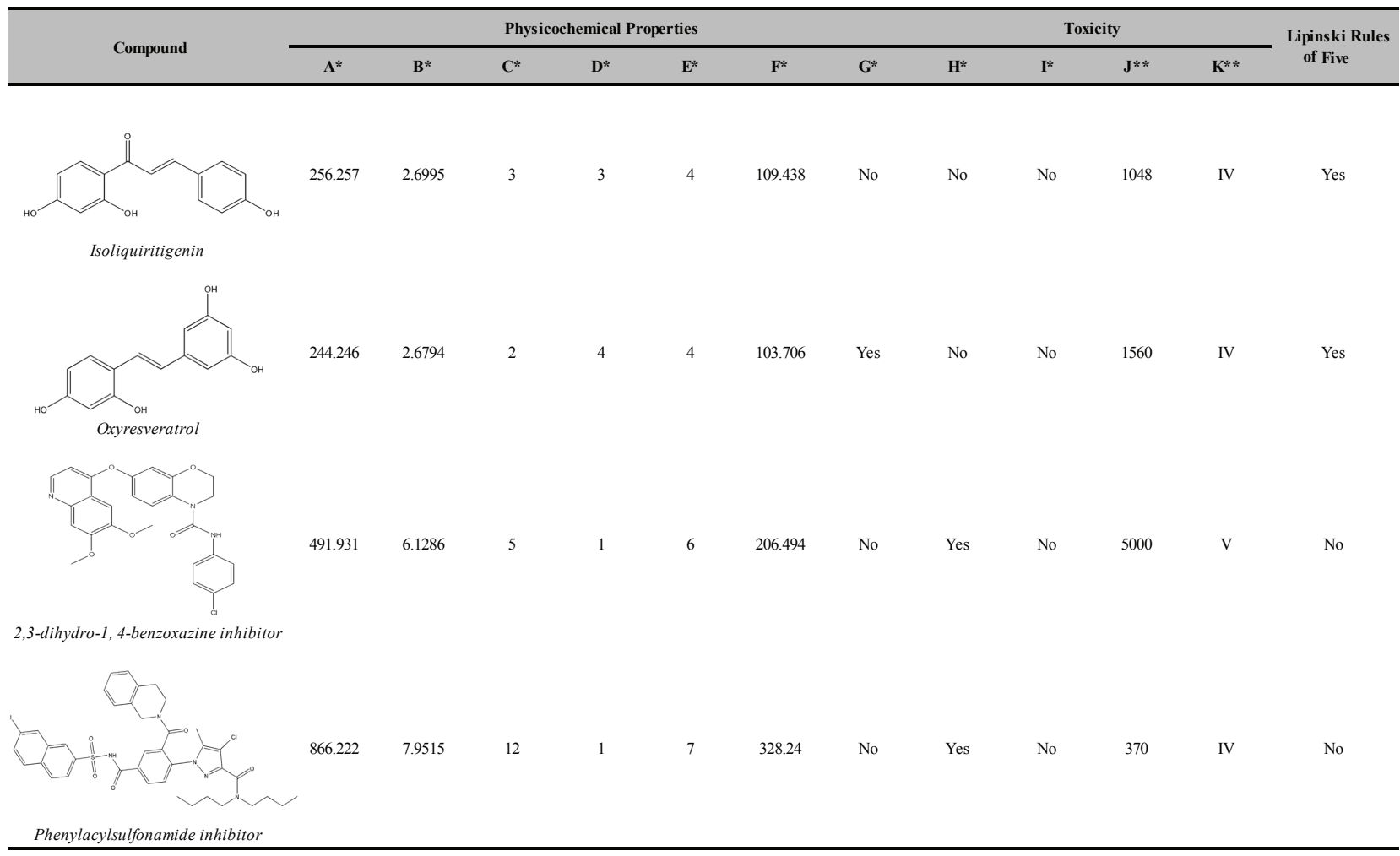

Description: A: Molecular Weight, B: Partition Coefficient, C: Number of Rotatable Bonds (Torsion), D: Hydrogen Bond Donors (HBD), E: Hydrogen Bond Acceptors (HBA), F: Polar Surface Activity, G: AMES Mutagenic Test, H: Toxic to the liver, I: Skin sensitization, J: $\mathrm{LD}_{50}(\mathrm{mg} / \mathrm{kg})$, K: Toxicity classes. class IV= harmfull is swallow (300-2000) Class IV = maybe harmful swallow (2000-5000). *pkCSM Online Tool **Protox II Online Tool. 
The results of toxicity prediction show that the test compounds of isoliquiritigenin and oxyresveratrol and the comparative compound phenylacylsulfonamide inhibitor belong to category four toxicity, namely slightly toxic (lethal dose (LD) $500-2000 \mathrm{mg} / \mathrm{kg}$ body weight (BW)). Comparative compounds (2,3-dihydro-1, 4-benzoxazine inhibitors) are included in category five toxicity, namely practically nontoxic $\left(\mathrm{LD}_{50} 2000-5000 \mathrm{mg} / \mathrm{kg} \mathrm{BW}\right.$ ). The toxicity prediction results of isolquiritigenin, oxyresveratrol, and comparative compounds are presented in Table 1. Based on Table 1, isoliquiritigenin compound was not mutagenic in the AMES mutagenic test, no hepatotoxic in hepatotoxicity tests and no cause skin irritation in skin sensitization tests. Oxyresveratrol compound showed that is mutagenic in AMES mutagenic test, but did not cause hepatotoxicity and skin sensitization. Both comparative compounds could be predicted to be hepatotoxic but no mutagenic and no toxic to the skin.

\section{Validation of Receptor}

The RMSD values between the generated poses and the bound native ligand of crystal structure VEGFR-2 (2RL5) and BCL-2 (4AQ3) are shown in Table 2. Based on Table 2 Validation results are shown with the RMSD value. Valid RMSD values lass then $2 \AA$ (Hevener. et al., 2009). It was found that poses receptors with native ligand has valid. RSMD in VEGFR-2 show value $1.18875 \AA$ and RMSD in BCL-2 chain $\mathrm{E}$ is lower than all chain with value RMSD $0.780526 \AA$.

\section{Docking Molecular and Interaction}

The result of molecular docking and interactions get the best position between ligands and receptors. The best position that has been done was where the ligand attaches to the receptor. The results of the best position of the test ligands and native ligands on the VEGFR-2 and BCL-2 Chain E receptors are shown in Figure 1. VEGFR-2 showed hydrogen bond and steric in-

Table 2. Validation receptor and RMSD values.

\begin{tabular}{cccccccc}
\hline Receptor & VEGFR-2 & BCL-2 Chain A & BCL-2 Chain B & BCL-2 Chain C & BCL-2 Chain D & BCL-2 Chain E & BCL-2 ChainF \\
\hline RMSD values & 1.18875 & 4.43089 & 11.3424 & 2.76257 & 10.8581 & 0.780526 \\
\hline
\end{tabular}
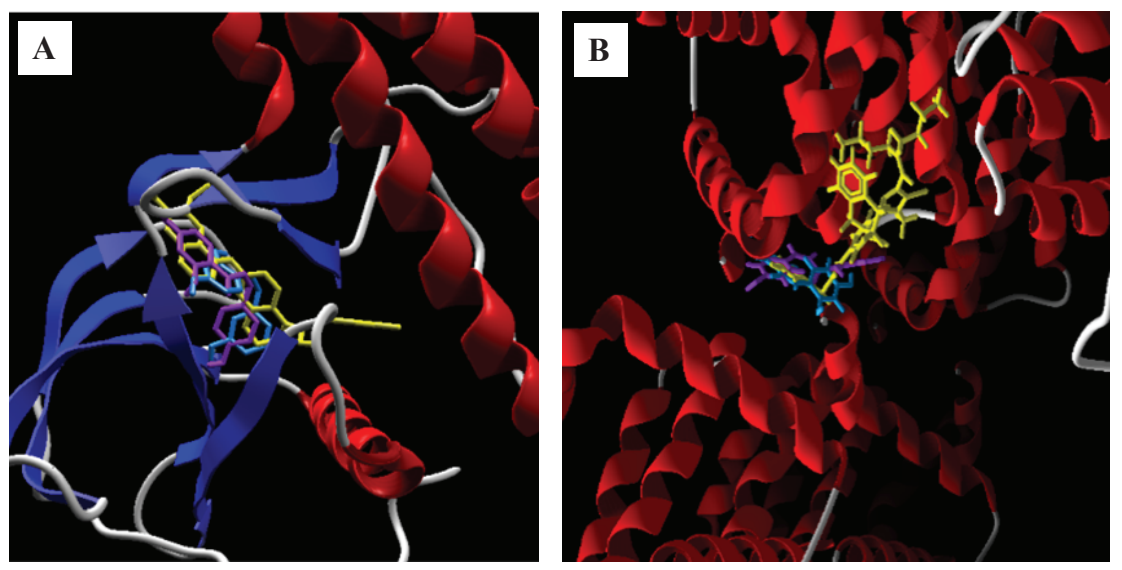

Figure 1. The two-dimensional interactions are shown between the test compounds against the VEGFR-2 (A) and $\mathrm{BCL}-2$ Chain $\mathrm{E}(\mathrm{B})$ receptors with their respective native ligands. 

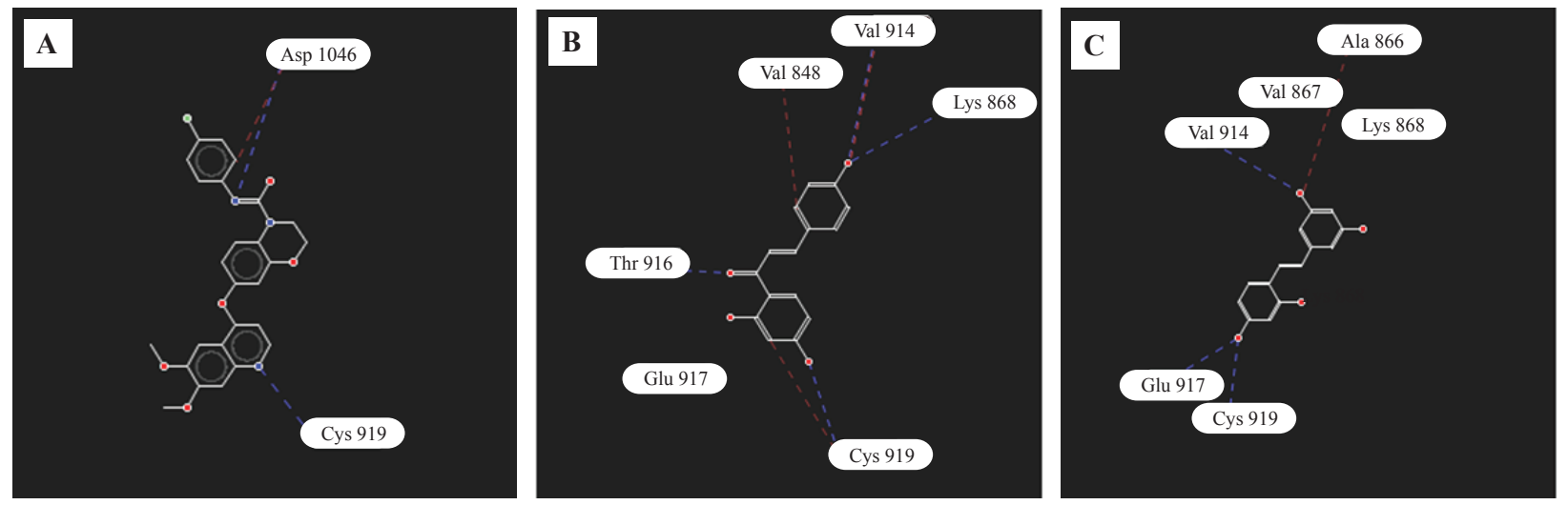

Figure 2. Two dimensions form of hydrogen and steric bonds between (A) 2,3-dihydro-1, 4-benzoxazine inhibitors (B) Isoliquiritigenin and (C) Oxyresveratrol with VEGFR-2 receptors (2RL5); blue lines as hydrogen bonds and red lines as steric bonds.

teraction that occurs between amino acid receptors and ligands. The ligand isoliquiritigenin had hydrogen bonds with amino acids Thr 916, Cys 919, Lys 868, Val 914 and steric bonds Cys 919, Val 848 , Val 914 . The ligand oxyresveratrol had hydrogen bonds with amino acids Glu 917, Cys 919, Lys 868, Val 914 and steric bond Ala 866. The native ligand 2,3-dihydro-1,4-benzoxazine inhibitors had hydrogen bonds with amino acids Cys 919, Asp 1046, and steric bonds Asp 1046. The bond results with the amino acid VEGFR-2 are presented in Figure 2. BCL-2 showed hydrogen bond and steric interac- tion that occurs between amino acid receptors and ligands. The ligand of isoliquiritigenin had hydrogen bonds with amino acids Arg 66 (E), Asp 62 (A), Arg 105 (E), Tyr 67 (E) and steric bonds Gly 104 (E),Arg 66 (E). The ligands of oxyresveratrol had hydrogen bonds with amino acids Leu 160 (A), Ala 59 (E), Gln 58 (A), Tyr 67 (E). The native ligands had hydrogen bonds with amino acids Gly 162 (A), Gln 58 (A), Tyr 67 (E) and steric interaction Phe 63 (E), Leu 96 (E), Glu 95 (E). The bond results between the amino acid and BCL-2 are shown in Figure 3.
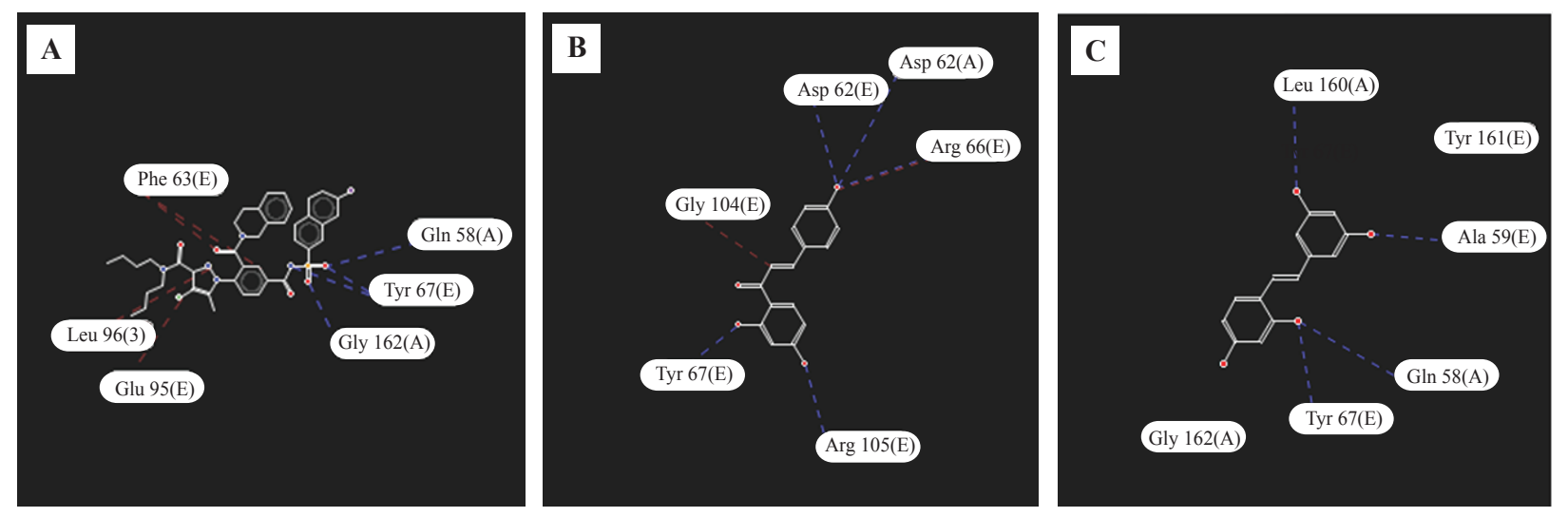

Figure 3. Two dimensions from of hydrogen bonds between (A) Phenyl-acyl-sulfonamide inhibitor (B) Isoliquirtigenin and $(C)$ Oxyresveratrol with receptor BCL-2 (4AQ3); blue lines as hydrogen bonds and red lines as steric interaction. 
The docking results between isoliquiritigenin and oxyresveratrol compounds to both VEGFR-2 receptor (2RL5) and native ligand 2,3-dihydro-1,4-benzoxazine inhibitors, then to both BCL-2 Chain E receptors (4AQ3-E) and native ligands phenylacylsulfonamide inhibitors had a ranging of RS from -68.0282 to $-123,998$. The two test ligands had a RS greater than the native ligand of each receptor. The docking results show that each receptor has the same amino acid at the VEGFR-2 receptor, Cys 919 and BCL-2, Tyr 67. The docking results are presented in Table 3.

\section{DISCUSSION}

This study aims to predict the physicochemical properties, toxicity and cytotoxic activity through in silico test of isoliquiritigenin and oxyresveratrol compounds. In both compounds test, isoliquiritigenin and oxyresveratrol fulfill the Lipinski rules of five with the meaning that it can be absorbed well and had good permeability while the comparative compounds did not meet the Lipinski rules of five because it have a molecular weight of $\geq 500$ and $\mathrm{HBA} \geq 10$. All compounds have $\mathrm{LD}_{50}$ value between $500-2000 \mathrm{mg} / \mathrm{kg}$ BW with $\mathrm{V}$ and IV grade toxicity which showed relatively low toxicity. The higher the $\mathrm{LD}_{50}$ value, the lower the toxicity (Supandi, et al., 2018). The compound will be difficult to absorb and its permeability is low if it has: its molecular weight is $\geq 500$, the $\log$ value of the partition coefficient is octanol/water $(\log \mathrm{P}) \geq$ +5 ; donor H-bond (HBD), expressed by the number of $\mathrm{OH}$ and $\mathrm{NH}$ groups, $\geq 5$; and H-receptor bonds (HBA) expressed by the number of atoms $\mathrm{O}$ and $\mathrm{N}, \geq 10$ (Lipinski, et al., 1997). Through fulfilling the Lipinski rules of five criterias, showed that isoliquiritigenin and oxyresveratrol compounds had good absorption and permeability.

Native ligands of 2RL5 and 4AQ3 coordinates were used for all docking experiments. In ordered to validate the scoring function, before redocking molecules for selecting prospective hits, we preparation into $2 \mathrm{RL} 5$ and $4 \mathrm{AQ} 3$ protein structure in MVD. there is one chain of VEGFR-2 protein in 2RL5 were each charged with its ligand and There are 6 chains of BCL-2 protein in 4AQ3 were each charged with its ligand. Subsequently, we compared the conformation and position with the bound ligand conformation measured regarding the rootmean square deviation (RMSD). Isoliquiritigenin and oxyresveratrol structures are docked to the receptor at the same place and coordinates previously.

In Table 3, the RS of VEGFR-2 receptor with an oxyresveratrol ligand had a smaller than ligand isoliquiritigenin, but the two test ligands are still higher when compared to native ligands 2,3-dihydro-1,4-benzoxazine inhibitors. This might be caused the hydrogen bond in the native ligand was more on the active side. The RS of BCL-2 receptor and oxyresveratrol ligand had a smaller value than the isoliquiritigenin ligand but the two ligands are not smaller than the native ligand (phenylacylsulfonamide inhibitor). A low RS can be attributed to the interaction of active amino acid bonds and also a less strong bond distance. RS or bond energy was the total calculation of all existing bonds. Bond energy stated the amount of energy needed to carry out interactions between ligands and receptors (Nugroho, 2014). The smaller RS indicates more stable bonds and results in increased activity (Thomsen, et al., 2006; Hincliffe, 2008; Kusumaningrum, et al., 2014; Hardjono, 2012).

The similarity of Cys 919 amino acid residue involved in the binding process of the VEGFR-2 receptor will cause the compound to inhibit the receptor activity by competitive inhibitors (Figure 2). This mechanism occured through the blockade of tyrosine kinase activation from VEGFR-2 (Hoi, et al., 2014). It was reported in previous studies that the interaction of ligands with amino acids Cys 919 can be observed as the active side (La, et al., 2008). Amino acid Lys 868 can be responsible as the active side and increase receptor bond energy (Ebadi, et al., 2012). The role of Glutamic Acid (Glu) in hydrogen bonds has been explained to have 
Indonesian Journal of Cancer Chemoprevention, June 2019

Table 3. Rerank score, hydrogen bond and steric interaction.

\begin{tabular}{|c|c|c|c|c|}
\hline Receptors & Compounds & 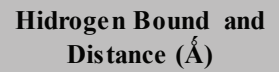 & $\begin{array}{c}\text { Steric Inte raction and } \\
\text { Distance }(\hat{\AA})\end{array}$ & Rerank Score \\
\hline \multirow{10}{*}{ 2RL5 } & \multirow{2}{*}{$\begin{array}{c}\text { 2,3-dihydro-1,4- } \\
\text { benzoxazine inhibitor }\end{array}$} & Cys 919 (2.87) & \multirow{2}{*}{ Asp 1046 (3.15) } & \multirow{2}{*}{-123.998} \\
\hline & & Asp 1046 (2.70) & & \\
\hline & \multirow{4}{*}{ Isoliquiritigenin } & Thr 916 (3.16) & Cys 919 (3.04) & \multirow{4}{*}{-68.0282} \\
\hline & & Cys 919 (3.06) & Val $848(3.02)$ & \\
\hline & & Lys 868 (2.93) & \multirow{2}{*}{ Val 914 (2.99) } & \\
\hline & & Val 914 (2.18) & & \\
\hline & \multirow{4}{*}{ Oxyresveratrol } & Glu 917 (3.01) & \multirow{4}{*}{ Ala $866(3.07)$} & \multirow{4}{*}{-73.0413} \\
\hline & & Cys 919 (2.94) & & \\
\hline & & Lys 868 (3.14) & & \\
\hline & & Val 914 (3.14) & & \\
\hline \multirow{11}{*}{ 4AQ3-E } & \multirow{3}{*}{$\begin{array}{c}\text { Phenylacylsulfonamide } \\
\text { inhibitor }\end{array}$} & Gly 162 (A) (3.11) & Phe 63(E) (3.15) & \multirow{3}{*}{-123.174} \\
\hline & & Gln 58 (A) (2.81) & Leu 96(E) (3.07) & \\
\hline & & Tyr 67 (E) (3.10) (3.19) & Glu 95(E) (3.14) & \\
\hline & \multirow{4}{*}{ Isoliquiritigenin } & Arg 66 (E) (3.04) & Gly 104(E) (2.98) & \multirow{4}{*}{-78.5041} \\
\hline & & Asp 62 (A) (2.74) & Arg 66 (E) (3.06) & \\
\hline & & $\operatorname{Arg} 105$ (E) (2.63) & & \\
\hline & & Tyr 67 (E) (3.05) & & \\
\hline & \multirow{4}{*}{ Oxyresveratrol } & Leu 160 (A) (3.06) & & \multirow{4}{*}{-87.9985} \\
\hline & & Ala 59 (E) (2.58) & & \\
\hline & & Gln 58 (A) (3.09) & & \\
\hline & & Tyr 67 (E) (3.12) & & \\
\hline
\end{tabular}

a role in inhibiting tumor development by suppressing the process of angiogenesis and permeability through the VEGFR-2 pathway (Baek, et al., 2017).

The similarity of tyrosine (Tyr) 67 (E) amino acid residue in both ligand and native ligand inhibitors test found that these amino acids were the active side of the BCL-2 receptor (4AQ3) (Figure 3). The Tyr 67 (E) amino acid residue is found in the BH-3 domain of BCL-2 (Kennedy, et al., 2015). This bond resulted in the activation of $\mathrm{BH}-3$ as pro-Apoptosis. Pro-apoptosis will compete with anti-apoptosis, so when more apoptosis will mediate the release of cytochrome-C from mitochondria. After cytochrome-C exits from the mitochondria cytochrome-C will be bound by Apaf-1 (Apoptosis
Activating Factor), then it will be bound and form a CARD domain (Caspase Recruitment Domain) and form Apoptosome. Apoptosome will activate caspase 9 then activate caspase 3. Caspase 3 is a mediator of cell death (apoptosis) (Chipuk, et al., 2010).

\section{CONCLUSION}

Isoliquiritigenin and oxyresveratrol compounds complied Lipinski rules of five and have a low toxicity. Oxyresveratrol compound had greater activity than isoliquiritigenin caused had lower rerank score. The activity of oxyresveratrol was also shown by hydrogen bonds in active amino acids (2RL5: Cys 919 in 4AQ3: Tyr 67). 


\section{ACKNOWLEDGEMENTS}

Thank you to Prof. Dr. Siswandono, Apt., M.S. for giving access to the application of Molegro Virtual Docker 5.5.

\section{REFERENCES}

Ayeka, P.A., Bian, Y., Mwitari, P.G., Chu, X., Zhang, Y., Uzayisenga, R. and Otachi, E.O., 2016, Immunomodulatory and anticancer potential of Gan cao (Glycyrrhiza uralensis Fisch.) polysaccharides by CT-26 colon carcinoma cell growth inhibition and cytokine IL-7 upregulation in vitro, BMC complementary and alternative medicine, 16, 206.

Baek, Y.Y., Lee, D.K., Kim, J., Kim, J.H., Park, W., Kim, T., Han, S., Jeoung, D., You, J.C., Lee, H., Won, M.H., Ha, K.S., Kwon, Y.G. and Kim, Y.M., 2017, Arg-Leu-Tyr-Glu Tetrapeptide Inhibits Tumor Progression By Suppressing Angiogenesis and Vascular Permeability Via Vegf Receptor-2 Antagonism, Oncotarget, 8(7), 11763-11777.

Cao, Y., Wang, Y., Ji, C. and Ye, J., 2004, Determination of Liquiritigenin and Isoliquiritigenin In Glycyrrhiza Uralensis and Its Medicinal Preparations By Capillary Electrophoresis With Electrochemical Detection, Journal of Chromatogr A, 1042, 203-209.

Chan, S.C., Chang, Y.S., Wang, J.P., Chen, S.C. and Kuo, SC., 1998, Three new flavonoids and antiallergic, anti-inflammatory constituents from the heartwood of Dalbergia odorifera, Planta Medica, 64, 153-158.

Chipuk, J.E., Moldoveanu, T., Llambi, F., Parsons, M.J. and Green, D.R., 2010, The BCL-2 family reunion, Molecular cell, 37, 299-310.

CLCbio, 2013, Molegro Virtual Docker User Manual, MVD 2013.6.0 for Windows, Linux, and Mac OS $X$, Molegro A CLC bio company.

Drwal, M.N., Banerjee, P., Dunkel, M., Wettig, M. R. and Preissner, R., 2014, ProTox: a web server for the insilico prediction of rodent oral toxicity, Nucleic Acids Research, 42(W1), W53-W58.

Ebadi, A., Razzaghi-Aslc,N., Shahabipour, S. and Miri, R., 2014, Ab-Initio And Conformational Analysis of A Potent Vegfr-2 Inhibitor: A Case Study on Motesanib, Ira nian Journal of Pharmaceutical Research, 13(2), 405-415.

Ferrara, N., 2009, VEGF-A: a critical regulator of blood vessel growth, Eur. Cytokine Netw., 20(4), 158-163.

Hardjono, S., 2012, Modifikasi struktur 1-(benzoiloksi) urea dan hubungan kuantitatif struktur-aktivitas sitotoksiknya [modification of 1-(benzoyloxy) urea structure and the quantitative relationship between its structure and cytotoxic activities], Dissertation. [Surabaya]: Airlangga University.

Hinchliffe, A., 2008, Molecular Modeling for Beginners. 2nd ed., Chichester: John Wiley and Sons Ltd.

Hoi, P.M., Li, S., Vong, C.T., Tseng, H.H.L., Kwan, Y.W. and Lee, S.M-Y., 2014, Recent Advances in Structure-Based Drug Design and Virtual Screening of Vegfr Tyrosine Kinase Inhibitors, Methods, 71, 85-91.

Igney F.H. and Krammer P.H., 2002, Review: death and antideath: tumor resistance to apoptosis, Nat Rev Cancer, 2(4), 277-88.

Jeltsch, M., Leppänen, V.M., Saharinen, P. and Alitalo, K., 2013, Receptor tyrosine kinase-mediated angiogenesis, Cold Spring Harb Perspect Biol., 15(9), a009183.

Kape, R., Parniske, M., Brandt, S. and Werner, D., 1992, Isoliquiritigenin, A Strong Nod Gene- and Glyceollin Resistance-inducing Flavonoid from Soybean Root Exudate, Appl Environ Microbiol., 58, 1705-1710.

Kartasasmita, R.E., Herowati, R. and Gusdinar, T., 2010, Docking Study of Quercetin Derivatives on Inducible Nitric Oxide Synthase and Prediction of Their Absorption and Distribution Properties, Journal of Applied Sciences, 10 (23), 3098-3104.

Kennedy, R.K., Veena, V., Ravindra, P., Naik, Lakshmi, P., Krishna, R., Sudharani, S. and Sakthivel, N., 2015, Phenazine-1-carboxamide (PCN) from Pseudomonas sp. strain PUP6 selectively induced apoptosis in lung (A549) and breast (MDA MB-231) cancer cells by inhibition of antiapoptotic Bcl-2 family proteins, International Journal on Programmed Cell Death, 20(6), 858-868.

Kinghorn, A.D., Drug discovery from natural products. In: Lemke, TL.; Williams, DA., Foye's, 2008, 
Principles of Medicinal Chemistry. 6th Edition. Philadelphia, PA, USA: Wolters Kluwer/Williams \& Wilkins.

Kumar, V., Cotran, R.S. and Robins, S., 2005, Basic Pathology 7th Ed. Penerbit Buku Kedokteran EGC, Jakarta.

Kusumaningrum, S., Budianto, E., Kosela, S., Sumaryono, W. and Juniarti, F., 2014, The molecular docking of 1,4-naphthoquinone derivatives as inhibitors of Polo-like kinase 1 using Molegro Virtual Docker, Journal of Applied Pharmaceutical Science, 4(11), 047-053

La, D.S., Belzile, J., Bready, JV., Coxon, A., DeMelfi, T., Doerr, N., Estrada, J., Flynn, J.C., Flynn, S.R., Graceffa, R.F., Harriman, S.P., Larrow, J.F., Long, A.M., Martin, M.W., Morrison, M.J., Patel, V.F., Roveto, P.M., Wang, L., Weiss, M.M., Whittington, D.A., Teffera, Y., Zhao, Z., Polverino, A.J. and Harmange, J.C., 2008, Novel 2,3-dihydro-1,4-benzoxazines as potent and orally bioavailable inhibitors of tumor-driven angiogenesis, Journal of Medicinal Chemistry, 51(6), 1695-1705.

Lipinski, C.A., Lombardo, F., Dominy, B.W. and Feeney, F.J., 1997, Experimental and computational approaches to estimate solubility and permeability in drug discovery and development settings, Advanced Drug Delivery Reviews, 23, 3-25.

Liu, Y.M., Ni, L.Q.,Wang, S.S,, Lv, Q,L,, Chen, W.J. and Ying, S,P., 2018, Outcome and prognostic factors in cervical cancer patients treated with surgery and concurrent chemoradiotherapy: a retrospective study, World Journal of Surgical Oncology, 16(18), 1-7.

Martel, C.D., Plummer, M., Vignat, J. and Franceschi, S., 2017, Worldwide burden of cancer attribut- able to HPV by site, country and HPV type, International Journal of Cancer, 141, 664-670.

Minggarwati, 2017, Uji Aktivitas Antikanker dan Identifikasi Senyawa Aktif dari Fraksi Umbi Bawang Sabrang (Eluetherine palmifolia (L.) Merr.) Terhadap, Sel Kanker Hela. [SKRIPSI]. Malang. Universitas Islam Negeri Maulana Malik Ibrahim Malang.

Pan, X., Kong, L., Zhang, Y., Cheng, C. and Tan, R., 2000, In Vitro Inhibition of Rat Monoamine Oxidase by Liquiritigenin and Isoliquiritigenin Isolated from Sinofranchetia Chinensis, Acta Pharmacol Sin., 21, 949-953.

Pires, D.E.V., Blundell, T.L. and Ascher, D.B., 2015, pkCSM: Predicting Small-Molecule Pharmacokinetic and Toxicity Properties Using Graph-Based Signatures, Journal of Medical Chemistry, 58, 4066-4072.

Rastogi, R.P. and Sinha, R.P., 2009, Apoptosis: molecular mechanisms and pathogenicity, EXCLI Journal, 8, 155-181.

Siswandono, editor, 2016, Kimia medisinal I [Medicinal chemistry I], 2nd edition, Surabaya, Airlangga University Press.

Sun, S., Hail Jr., N., and Lotan, R., 2004, Apoptosis as a novel target for cancer chemoprevention, Journal of the National Cancer Institute, 96(9), 662-272.

Supandi., Yeni. and Merdekawati F., 2018, In Silico Study of Pyrazolylaminoquinazoline Toxicity by Lazar, Protox, and Admet Predictor, Journal of Applied Pharmaceutical Science, 8(09), 119-129.

Thomsen, R. and Christensen, M.H., 2006, Mol Dock: A New Technique for High-Accuracy Molecular Docking, Journal of Medical Chemistry, 49(11), 3315-3321. 